TRABAJOS DE PREHISTORIA

68, N. ${ }^{\circ} 2$, julio-diciembre 2011, pp. 259-274, ISSN: 0082-5638

doi: $10.3989 /$ tp.2011.11069

\title{
Convenciones gráficas en el arte parietal del Paleolítico cantábrico: la perspectiva de las figuras zoomorfas
}

\author{
Graphic conventions in Cantabrian Paleolithic Rock Art: The perspective of zoomorphic \\ figures
}

Aitor Ruiz Redondo (*)

\section{RESUMEN}

La cuestión de la perspectiva mostrada por las representaciones animales paleolíticas ha interesado a los investigadores desde principios del siglo XX. Tradicionalmente ha servido para argumentar un fenómeno de evolución lineal hacia la consecución de la maestría en la representación gráfica. En las últimas décadas, este modelo evolucionista ha entrado en crisis, poniendo en duda lo anteriormente conocido en materia de perspectiva. Para afrontar esta cuestión, hemos analizado de forma cuantitativa, positiva e individualizada algunas características de las figuras zoomorfas de 11 conjuntos gráficos parietales. Los resultados obtenidos abogan por la existencia de distintos grupos de conjuntos rupestres paleolíticos en el ámbito cantábrico. Además, proponemos que las diferencias entre los comportamientos gráficos de estos grupos están directamente relacionados con la existencia de un marco cronológico distinto para cada uno de ellos.

\begin{abstract}
The question of the perspective shown by Paleolithic animal representations has interested researchers since the early twentieth century. Traditionally it has been used to support a phenomenon of linear evolution towards the attainment of expertise in graphic representation. In recent decades, this evolutionary model has been in crisis, questioning what was previously known about the perspective. To address this issue, we have analyzed quantitatively, practically and individually some zoomorphic characteristics of 11 Cantabrian rock art localities. The results argue for the existence of different groups of $\mathrm{Pa}$ laeolithic rock art sites in the Cantabrian area. Moreover,
\end{abstract}

(*) Instituto Internacional de Investigaciones Prehistóricas de Cantabria (IIIPC). Universidad de Cantabria. Edificio Interfacultativo. Avda. Los Castros s/n. 39005 Santander. Correo e.: aitor.ruiz@unican.es

Recibido: 23-XII-2010; aceptado: 12-II-2011. we propose that the different graphic behaviors of these groups are directly related to the existence of a different chronology for each of them.

Palabras clave: Paleolítico superior; Arte parietal; Península Ibérica; Cronología; Análisis multivariante; Historiografía.

Key words: Upper Palaeolithic; Rock Art; Iberian Peninsula; Chronology; Multivariate analysis; Historiography.

\section{INTRODUCCIÓN}

La plasmación de la tercera dimensión en una representación gráfica bidimensional exige la adopción de uno o varios puntos de vista por parte del artista. En el estudio del arte paleolítico tradicionalmente se ha definido una serie de "tipos de perspectiva". Uno de los primeros autores que evaluó esta cuestión fue H. Breuil, que en algunos de sus trabajos iniciales anotaba los diferentes puntos de vista adoptados en una misma figura (Alcalde del Río et al. 1911: 58). Posteriormente clasificó la perspectiva mostrada por los cuernos de las figuras zoomorfas en tres categorías: "torcida", "semi-torcida" y "correcta", cuya sucesión cronológica conducía a una progresiva complejidad y maestría en la expresión gráfica (Breuil 1952: 39). Esta clasificación sólo quedaba más o menos implícita en sus valoraciones de las figuras rupestres (Breuil 1952: 40).

A partir de la segunda mitad del siglo XX las teorías de A. Leroi-Gourhan se convierten en el nuevo paradigma de los especialistas en el arte rupestre paleolítico. Su principal diferencia con 
H. Breuil es que definió explícitamente los tipos de perspectiva y las implicaciones derivadas de la presencia de uno u otro. Ambos investigadores compartían una interpretación evolucionista del arte, por lo que explicaban las modificaciones en materia de perspectiva como resultado de la progresiva adquisición de un mayor grado de "maestría" al representar la tercera dimensión (LeroiGourhan 1983: 34). Según el tradicional esquema que llevaba "de lo simple a lo complejo", equiparaban los distintos tipos a estadios evolutivos en materia artística. Leroi-Gourhan caracterizó cuatro "tipos de perspectiva" frecuentes en las figuras animales del arte pleistoceno: "perfil absoluto", "perspectiva biangular recta", "biangular oblicua" y "uniangular", si bien excepcionalmente puede hallarse alguna representación en perspectiva "biangular o pluriangular opuesta", como algún mamut de La Baume Latrone (Leroi-Gourhan 1983: 32). Las implicaciones de este esquema evolucionista son difícilmente asumibles en la actualidad. La evolución unilineal defendida por H. Breuil y A. Leroi-Gourhan presupone una continuidad de 30.000 años para el significado y el contexto en que se produce el arte paleolítico (Conkey 1985: 301). Además, desde comienzos de la década de 1990, nuevos conjuntos parietales (Chauvet, Cosquer, valle del Côa...) y revisiones de otros (Parpalló) no encajan en los esquemas de dichos investigadores franceses.

Nuestra propuesta se basa en un análisis comparativo que englobe a varias cavidades con arte rupestre paleolítico de la región cantábrica. El objetivo es calibrar los factores que condicionan la utilización de los tipos de perspectiva en el Paleolítico superior. La cuestión principal es evaluar si, como defienden las interpretaciones tradicionales, las diferencias en la perspectiva de las figuras, su esquema compositivo e, incluso, temática, se deben a una mejora secuencial en la capacidad expresiva, al mensaje que se quiere transmitir (ubicación en la cueva, visibilidad...), al procedimiento de ejecución (técnicas aditivas o sustractivas) o a la búsqueda de un tratamiento esquemático frente al realista,como parecen sugerir los últimos hallazgos franceses en la materia (Chauvet, Cosquer...).

Analizaremos de forma cuantitativa y positiva la información disponible sobre los conjuntos a estudiar del arte paleolítico cantábrico, a tenor de los avances en materia de datación no estilística.
Algunos trabajos (Fortea 1994; González Sainz y Gárate 2006) han tratado sumariamente los tipos de perspectiva y la ordenación temporal de los más característicos en la región cantábrica, pero sólo hace poco (en el trabajo de investigación de tercer ciclo de quien suscribe estas líneas) han sido objeto de un estudio específico y de conjunto. La principal novedad de este trabajo radica en trascender el estudio individualizado de santuarios aplicando la misma metodología de análisis a varios grupos de yacimientos con arte rupestre. Esperamos que ello pueda ser de utilidad para incrementar nuestro conocimiento acerca del arte paleolítico cantábrico y, en la medida de lo posible, de sus autores.

\section{MATERIAL Y MÉTODO}

\subsection{Conjuntos rupestres estudiados}

Como en la región cantábrica, según los últimos recuentos (González Sainz 2007: 19), hay 114 conjuntos rupestres atribuibles al Paleolítico superior, se impone un muestreo. Hemos seleccionado 11 conjuntos (Fig. 1) cuyas representaciones, por su alto grado de homogeneidad interna, son $a$ priori sincrónicas. Evitamos los conjuntos más complejos y con mayor variabilidad interna, en principio expresiva de un lapso temporal más amplio, como, por ejemplo, El Castillo, Tito Bustillo, Peña Candamo, etc. Hemos dividido los conjuntos estudiados en tres grupos según sus características formales, técnicas y estilísticas.

Grupo 1. Está formado por conjuntos exteriores con grabado profundo. Están muy concentrados en la cuenca media del río Nalón (Santo Adriano, La Viña, La Lluera, Los Torneiros, Cueva Molín...). El resto se hallan más dispersos por el centro de la región (Chufín, Hornos de La Peña, Venta de la Perra, La Luz...). F. J. Fortea los definió y estudió bien, denominándolos "santuarios exteriores cantábricos" (Fortea 1994: 203204). Se caracterizan por las representaciones de ciervas "de cabeza trilineal", así como de bisontes acéfalos asociados a ellas en algunos conjuntos como Chufín, Hornos de La Peña... (González Sainz 2000). Fueron realizadas en su mayoría en paneles que reciben luz solar y habitualmente mediante la técnica del grabado profundo. Los conjuntos seleccionados son: Chufín (Almagro 1973; Almagro et al. 1977; González Sainz 2000,

Trab. Prehist., 68, N. ${ }^{\circ}$ 2, julio-diciembre 2011, pp. 259-274, ISSN: 0082-5638

doi: $10.3989 /$ tp.2011.11069 


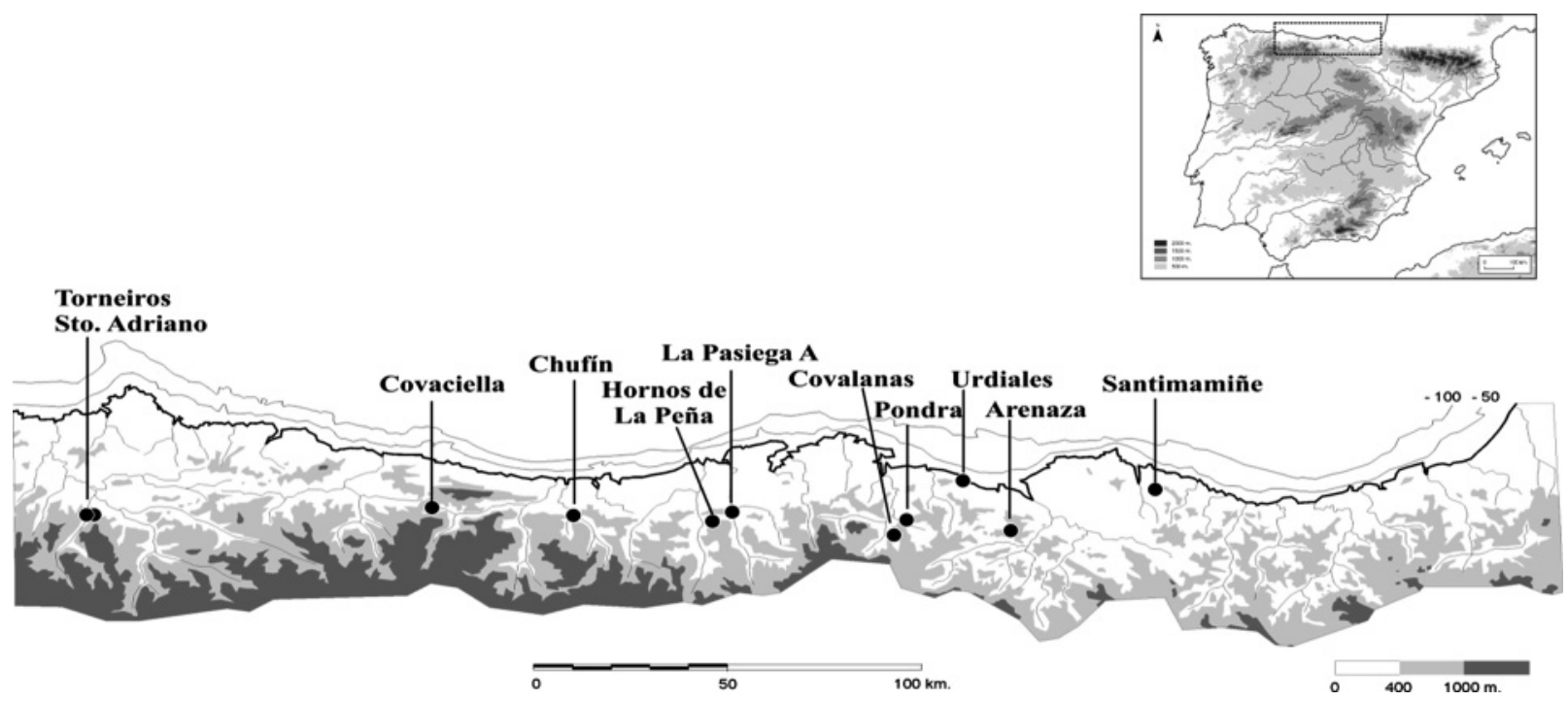

Fig. 1. Mapa de la costa cantábrica oriental con la ubicación de los conjuntos seleccionados para el estudio en la región cantábrica y la Península Ibérica: Torneiros y Santo Adriano (Santo Adriano, Asturias), Covaciella (Cabrales, Asturias), Chufín (Rionansa, Cantabria), Hornos de La Peña (San Felices de Buelna, Cantabria), La Pasiega (Puente Viesgo, Cantabria), Covalanas y Pondra (Ramales de la Victoria, Cantabria), Urdiales (Castro Urdiales, Cantabria), Arenaza (Galdames, Bizkaia) y Santimamiñe (Kortezubi, Bizkaia).

2010), Hornos de La Peña exterior (González Sainz 2000; Gálvez y Cacho 2010), Santo Adriano (Fortea y Quintanal 1995; Fortea 2005) y Los Torneiros (Fortea et al. 1999).

Grupo 2. Incluye conjuntos interiores con representaciones realizadas mediante "tamponado", "trazo punteado" o "trazo digital", en color rojo o más rara vez en amarillo. Emplearemos el primer término por ser el más tradicional y extendido, sin valorar ni discutir sus implicaciones técnicas. Son santuarios típicamente cantábricos, algunos conocidos desde antiguo (Covalanas fue descubierta en 1903). Recientemente se han analizado en profundidad y uno caracterizado de un modo exhaustivo (Gárate 2010). Seleccionados: Covalanas (Alcalde del Río et al. 1911; Moure et al. 1991; García Díez et al. 2003); Arenaza (Apellániz 1982; Gorrotxategi 2000; Gárate et al. 2002; Gárate 2004), Pondra (González Sainz y San Miguel 2001) y la Galería A de La Pasiega (Breuil et al. 1913; González Sainz y Balbín 2010).

Grupo 3. Incluimos aquí los conjuntos típicamente magdalenienses, de los que disponemos de una mayor cantidad de información en la actualidad (número de dataciones absolutas, estudios, bibliografía...). Poseen unas características comu- nes que permiten asignarlos a este grupo, sin embargo, la variabilidad interna (entre los distintos conjuntos o incluso entre representaciones del mismo conjunto en algunos casos) es mayor que en los otros grupos. En contraposición con los anteriores, estos conjuntos comparten más elementos con los de otras zonas (Pirineos, Dordogne...). En el ámbito cantábrico son ampliamente conocidos conjuntos como Santimamiñe, Cueva Urdiales, La Cullalvera, Ekain, la Covaciella, el "Gran Techo" de Altamira, atribuidos tradicionalmente al período Magdaleniense por analogía con las abundantes representaciones en soporte portátil de ese período. Los conjuntos incluidos son: Santimamiñe (Aranzadi et al. 1976; Gorrotxategi 2000) (1), Cueva Urdiales (Montes et al. 2005) y Covaciella (Fortea et al. 1995; Ríos González et al. 2007; Fortea 2008).

Nuestra hipótesis de partida es que la homogeneidad técnica de las figuras en cada grupo, ya destacada tradicionalmente, se ampliaría a una homogeneidad temática y estilística.

(1) González Sainz, C. y Ruiz Idarraga, R. (e.p.): Una nueva visita a Santimamiñe. Precisiones en el conocimiento del conjunto parietal paleolitico. Anejos de Kobie 11. Diputación foral de Bizkaia. Bilbao 2011. 


\subsection{Criterios analíticos}

\subsubsection{Tipo de animal}

Se ha identificado la especie del animal representado, con algunas excepciones. En el análisis de las representaciones de Cervus elaphus nos ha parecido relevante distinguir entre sexos. En la mayoría de los casos el dimorfismo sexual y los caracteres sexuales secundarios (cornamenta en los machos) aparecen plasmados, permitiendo esta distinción. Además, como se ha destacado tradicionalmente, la cierva - no tanto el ciervotiene un papel muy relevante en el arte paleolítico cantábrico. Por otro lado, cuando no se ha podido distinguir entre la figura de un uro (Bos primigenius) o un bisonte (Bison priscus), aunque sí que se trata de un animal de la subfamilia Bovinae, le asignamos la categoría "bóvido indeterminado". Se consideran "cuadrúpedo indeterminado" las figuras sin especie ni familia identificable.

En los conjuntos analizados, participan: caballo, ciervo, cierva, uro, bisonte, bóvido indeterminado, cabra, reno, oso, y cuadrúpedo indeterminado.

\subsubsection{Grado de integridad}

Hemos definido siete categorías (Fig. 2) para clasificar el grado de integridad de las figuras, es decir, las partes anatómicas representadas.

Figura completa (A): silueta completa, al menos con una extremidad por par. No importa si carece de detalles internos (ojos, orejas, pelaje...).

Figura completa acéfala (Aa): la silueta carece de la cabeza.

Figura semi-completa (B): faltan las extremidades anteriores o las posteriores.

Figura semi-simplificada (C): la silueta carece de uno de los trenes (anterior o posterior) y de alguna otra zona anatómica, como la cabeza, el pecho, el vientre, la línea cérvico-dorsal o la nalga.

Figura simplificada (D): reducida a la cabeza y línea cérvico-dorsal, pudiendo también presentar parte de la nalga y/o de la zona pectoral. Carece de las extremidades.

Cabeza aislada (E).

Otras partes aisladas (F): el artista sólo ha plasmado alguna de las partes anatómicas (una extremidad, una pezuña, unas astas, unos cuernos...).
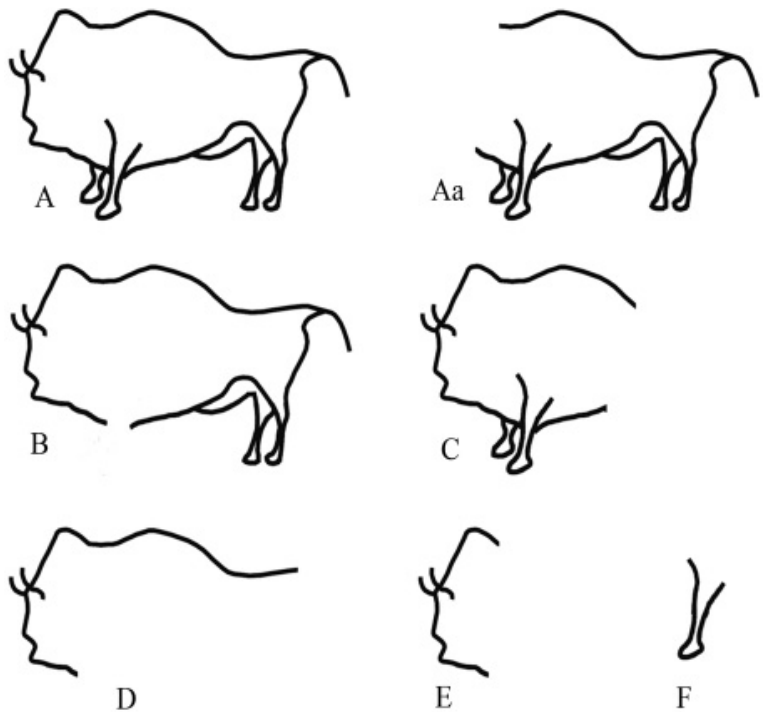

Fig. 2. Categorías para valorar el grado de integridad de las representaciones animales del Paleolítico Superior cantábrico, según Aitor Ruiz Redondo, en este trabajo: A. Figura completa; Aa. Figura completa acéfala; B. Figura semi-completa; C. Figura semi-simplificada; D. Figura simplificada; E. Cabeza aislada; F. Otras partes aisladas.

\subsubsection{Perspectiva general}

Adoptamos las categorías definidas por LeroiGourhan (1983: 32-33) para describir los "tipos de perspectiva" (Fig. 3):

1. Perfil absoluto: el animal está de perfil. Las partes anatómicas pares (extremidades, orejas, cuernos, astas...) se disponen en primer plano, lo que implica un "grado cero" de perspectiva. Leroi-Gourhan consideraba este tipo la forma más simple -y por lo tanto más antigua- de representación de las figuras animales. No tiene equivalencia en la clasificación de Breuil.

2. Perspectiva biangular recta: el animal se dispone alternativamente de frente y de perfil con un ángulo de separación de $90^{\circ}$ entre ambos puntos de vista. La silueta corporal se encuentra de perfil, mientras que las partes anatómicas pares se representan de frente. En realidad, A. LeroiGourhan sólo analizaba los tipos de perspectiva en los cuernos, astas u orejas, nunca en las extremidades. Es característica del Estilo II y, por lo tanto, asimilable a fases antiguas del Paleolítico superior. Este tipo equivale a la "perspectiva torcida" de H. Breuil. 


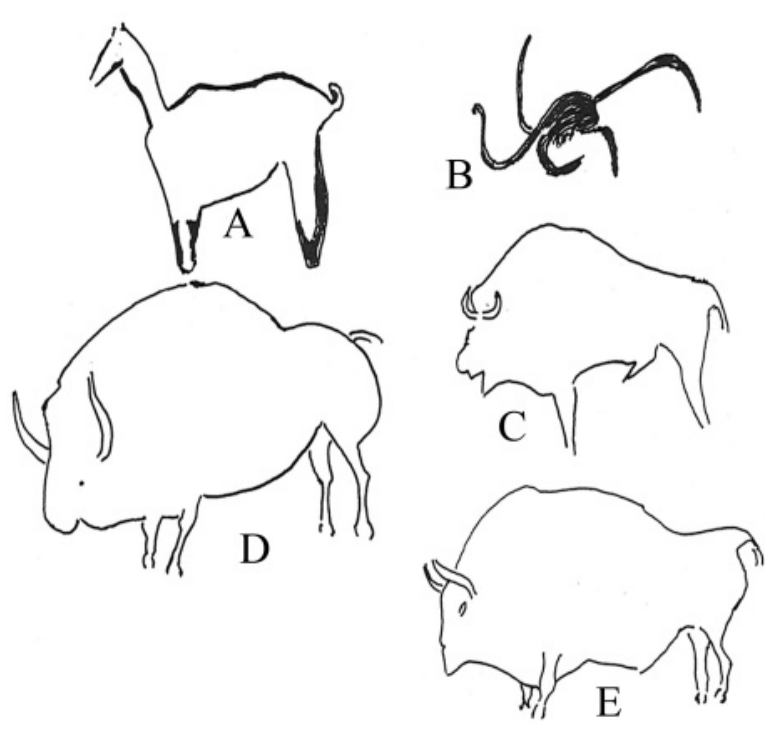

Fig. 3. Tipos de perspectiva en el grafismo del Paleolítico Superior según A. Leroi-Gourhan (1983: 33): A. Perfil absoluto (Belcayre, Dordoña); B. Perspectiva biangular opuesta (La Baume Latrone, Gard); C. Perspectiva biangular recta (La Grèze, Dordoña); D. Perspectiva biangular oblicua (La Mouthe, Dordoña); E. Perspectiva uniangular (Font-de-Gaume, Dordoña) (A, D y E invertidos). Sin escala en el original.

3. Perspectiva biangular oblicua: en este caso, el ángulo formado entre la vista de la silueta corporal -representada de perfil-y la de las partes anatómicas pares es de $45^{\circ}$. A. Leroi-Gourhan consideraba que este tipo de perspectiva era característico de su Estilo III, enmarcado entre los períodos Solutrense y Magdaleniense inferior. Fue definido por H. Breuil como "perspectiva semitorcida".

4. Perspectiva uniangular: figura y percepción visual del sujeto son idénticas. Se trata de la "perfección en la restitución de la tercera dimensión" (Aujoulat 1993: 283). Por ese mismo motivo, para A. Leroi-Gourhan este tipo de perspectiva constituye el culmen de milenios de evolución en materia de producción artística y por lo tanto caracteriza el Estilo IV, el último de ellos, que se desarrolla en la segunda parte del Magdaleniense. El equivalente en la clasificación de $\mathrm{H}$. Breuil es la "perspectiva correcta".

Como norma general, la perspectiva de cualquier figura es la que muestran todas sus partes anatómicas -en particular las pares-. ¿Pero qué ocurre cuando las distintas partes muestran diferentes tipos de perspectiva? V. Villaverde (1994:
86) enfrentó este problema en su estudio de las plaquetas de Parpalló. Hemos empleado su propuesta ya que creemos permite obtener resultados bastante fiables. Los criterios para establecer la perspectiva general son los siguientes. Cuando la perspectiva biangular recta $(\mathrm{BR})$ coincida con cualquier otra -biangular oblicua, perfil absoluto o uniangular-, se la considerará como dominante; si la biangular oblicua (BO) coincide con otra (salvo la biangular recta) será la dominante. Por último, si coincide la perspectiva uniangular (UN) con el perfil absoluto (PA), se seleccionará la primera, reservando la categoría de perfil absoluto para cuando no haya indicadores de perspectiva en ninguna parte anatómica de la figura.

\section{RESULTADOS}

Hemos transformado en porcentajes numéricos los datos de estos conjuntos referentes a la especie animal representada, el grado de integridad de la figuras y la perspectiva (Tab. 1), introduciéndolos en un programa informático de estadística aplicada a la Paleontología y la Arqueología, el PAST® (Paleontological Statistics).

Posteriormente, hemos hecho un análisis multivariante de correspondencias (Fig. 4). El objetivo de esta técnica estadística es transformar una tabla de frecuencias de aparición en una gráfica que facilite la interpretación de los datos (Barceló 2007: 124). De este modo, se pueden observar las afinidades y divergencias entre los yacimientos, valorando una suma de variables no relacionadas.

El análisis multivariante de correspondencias ha reafirmado la pertinencia de nuestra división por grupos. La temática animal, el tipo de perspectiva y el grado de integridad de las figuras parecen estar en consonancia con las características técnicas y estilísticas que diferencian a los Grupos 1, 2 y 3. A continuación detallamos la relación entre grupos y variables.

Grupo 1. La mayor parte de las representaciones de estos conjuntos carecen completamente de indicadores de perspectiva (perfil absoluto) y presentan algunas partes anatómicas de los animales (C o D). El porcentaje de caballos es el mayor de los tres grupos (si bien es una especie que aparece en todos, lo que explica su posición central). La especie predominante es la cierva, como en el Grupo 2 (se aprecia en la posición de este animal, casi equidistante entre ambos). 


\begin{tabular}{|c|c|c|c|c|c|c|c|c|c|c|c|c|}
\hline & & Chuf & SAdr & Horn & Torn & Cova & Aren & PasA & Sant & Urdi & Cvci & Pond \\
\hline \multirow{5}{*}{ A } & Caballo & 5 & 0 & 33,33 & 41,67 & 9,09 & 0 & 32,22 & 8,51 & 8,7 & 9,09 & 50 \\
& Ciervo & 0 & 3,13 & 0 & 0 & 0 & 7,14 & 16,67 & 2,13 & 0 & 9,09 & 16,67 \\
& Cierva & 75 & 75 & 33,33 & 33,33 & 81,82 & 85,71 & 36,67 & 2,13 & 0 & 0 & 33,33 \\
& Uro & 5 & 0 & 0 & 8,33 & 9,09 & 7,14 & 4,44 & 0 & 0 & 0 & 0 \\
& Bisonte & 15 & 12,5 & 33,33 & 0 & 0 & 0 & 5,56 & 61,7 & 73,91 & 72,73 & 0 \\
& Bóv. ind. & 0 & 0 & 0 & 0 & 0 & 0 & 0 & 2,13 & 0 & 0 & 0 \\
& Cabra & 0 & 6,25 & 0 & 0 & 0 & 0 & 2,22 & 10,64 & 8,7 & 0 & 0 \\
& Reno & 0 & 0 & 0 & 0 & 0 & 0 & 1,11 & 0 & 0 & 9,09 & 0 \\
& Oso & 0 & 0 & 0 & 0 & 0 & 0 & 0 & 2,13 & 0 & 0 & 0 \\
& Cuad. ind. & 0 & 3,13 & 0 & 16,67 & 0 & 0 & 1,11 & 10,64 & 8,7 & 0 & 0 \\
\hline \multirow{5}{*}{ B } & A+Aa+B & 15 & 50 & 0 & 41,67 & 54,55 & 57,14 & 41,11 & 74,47 & 82,61 & 72,73 & 33,33 \\
& C+D & 85 & 46,88 & 100 & 58,33 & 36,36 & 35,71 & 46,67 & 19,15 & 13,04 & 18,18 & 50 \\
& E+F & 0 & 3,13 & 0 & 0 & 9,09 & 7,14 & 12,22 & 6,38 & 4,35 & 9,09 & 16,67 \\
\hline \multirow{5}{*}{ C } & PA & 90 & 93,75 & 100 & 100 & 4,55 & 14,29 & 23,33 & 44,68 & 34,78 & 27,27 & 33,33 \\
& BR & 10 & 6,25 & 0 & 0 & 86,36 & 85,71 & 54,44 & 4,26 & 4,35 & 9,09 & 66,67 \\
& BO & 0 & 0 & 0 & 0 & 9,09 & 0 & 17,78 & 6,38 & 8,7 & 0 & 0 \\
& UN & 0 & 0 & 0 & 0 & 0 & 0 & 4,44 & 44,68 & 52,17 & 63,64 & 0 \\
\hline & TOTAL & 20 & 32 & 3 & 12 & 22 & 14 & 90 & 47 & 23 & 11 & 6 \\
\hline
\end{tabular}

Tab. 1. Arte paleolítico cantábrico. Resultados del análisis cuantitativo considerando la especie animal (A), el grado de integridad de la figura (B) (véase Fig. 2) y su perspectiva general (C), expresado en porcentaje respecto al total de figuras animales de cada conjunto. Las abreviaturas de la línea superior corresponden a los 11 conjuntos estudiados: Chufín, Santo Adriano, Hornos de la Peña, Los Torneiros, Covalanas, Arenaza, La Pasiega A, Santimamiñe, Cueva Urdiales, Covaciella y Pondra. Las abreviaturas en A: Bóv. Bóvido, Cuad. Cuadrúpedo, ind. Indeterminado; en C: PA perfil absoluto, perspectivas BR biangular recta, BO biangular oblicua, UN uniangular.

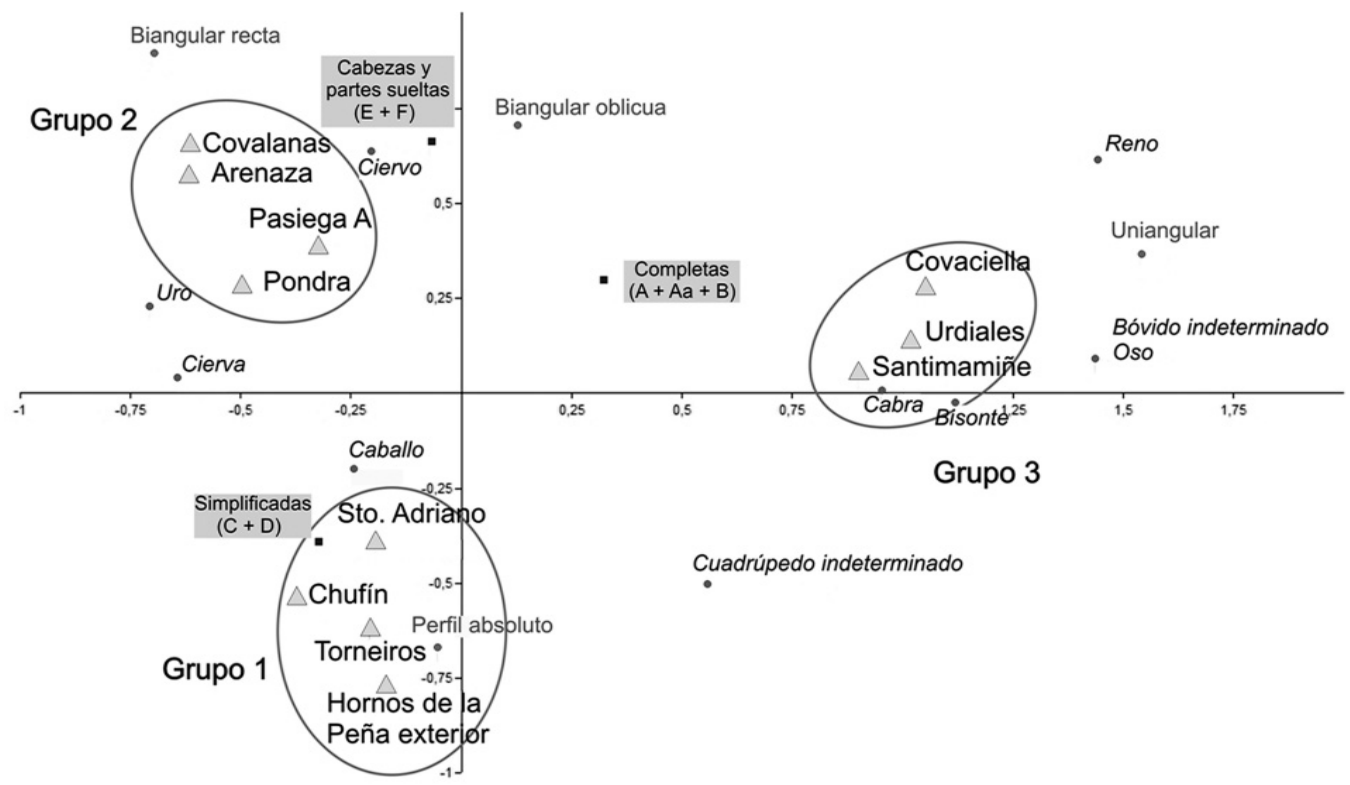

Fig. 4. Arte paleolítico cantábrico. Análisis multivariante de correspondencias de los 3 grupos definidos por la especie representada, el grado de integridad del animal (A, Aa, B, C, D, E, F: véase Fig. 2) y la perspectiva. Los conjuntos estudiados se simbolizan mediante un triángulo y las agrupaciones de conjuntos observables se destacan con unas elipses.

Trab. Prehist., 68, N. ${ }^{\circ}$, julio-diciembre 2011, pp. 259-274, ISSN: 0082-5638 doi: $10.3989 /$ tp.2011.11069 
Grupo 2. Sus animales presentan mayoritariamente una perspectiva biangular recta (BR) o biangular oblicua (BO). Muestra un elevado número de figuras con formatos completos o semi-completos (A, Aa y B), así como el mayor porcentaje de cabezas y partes anatómicas sueltas (E y F). Dominan las ciervas (igual que en el Grupo 1) y las mayores diferencias con otros grupos corresponden a los altos porcentajes de ciervos y uros.

Grupo 3. Las representaciones presentan mayoritariamente una perspectiva uniangular (UN). También es el grupo con un mayor porcentaje de figuras con todas o casi todas las partes anatómicas. A diferencia de los dos grupos anteriores, predominan el bisonte y la cabra (identificados, aunque con porcentajes muy inferiores, en los conjuntos del Grupo 1). Aparecen dos especies prácticamente inexistentes en los grupos anteriores: el reno y el oso.

Los tres grupos se hallan lo suficientemente distantes entre sí como para que no haya dudas sobre la pertenencia de algún conjunto a una u otra agrupación. Es decir, el análisis de correspondencias refleja con claridad que la división tripartita propuesta tiene una base fundamentada tanto en criterios técnico-artísticos como temáticos y estilísticos.

\section{DISCUSIÓN}

La distinción entre los tres grupos en función de la perspectiva, la temática y el grado de integridad de las figuras puede tener relación con una cronología particular. Es decir, la homogeneidad de cada agrupación podría ser reflejo de una cierta homogeneidad cronológica entre los centros pertenecientes a cada uno de los grupos, al menos por oposición a los de otros grupos. Interpretamos los análisis anteriores a partir de la información cronológica no estilística de que disponemos.

\subsection{Información cronológica no estilística}

\subsubsection{Grupo 1}

1. Las dataciones de la cueva de Venta de la Perra (Bizkaia). C. González Sainz (2000) argumentó satisfactoriamente la conveniencia de relacionar varios conjuntos de la región cantábrica.
Además de tratarse de conjuntos con grabados profundos realizados a la luz del día -lo cual ya permitiría establecer un cierto paralelismo-, identificó una coherencia entre las figuras arcaicas de bisontes acéfalos y las esquematizaciones de ciervas "de cabeza trilineal".

Ambos zoomorfos se asocian en conjuntos analizados, como los de Hornos de La Peña y Chufín. Además, por separado, encontramos este tipo de bisontes en Venta de la Perra, La Luz y Los Murciélagos y las ciervas en un buen número de conjuntos de Cantabria y de la cuenca del Nalón, como Torneiros y Santo Adriano. Los dos bisontes del interior de la cueva de Chufín son de idéntica factura y procedimiento técnico que el otro localizado en el exterior y otros, también a la luz del día en Hornos de La Peña, Los Murciélagos, La Luz y Venta de la Perra. Por lo tanto, se puede defender que se hicieron figuras en el interior de las cavidades en este horizonte artístico caracterizado básicamente por las exteriores (González Sainz 2000).

Recientemente hemos planteado la posibilidad de que las ciervas y los bisontes de estos tipos tengan una diferente distribución geográfica (Ruiz Redondo 2010). Los bisontes acéfalos más occidentales -ligeramente diferentes de los de $\mathrm{La}$ Lluera y Santo Adriano- se encuentran en Chufín, en la cuenca del Nansa, mientras que las ciervas más orientales "de cabeza trilineal" se hallan en Hornos de La Peña, en la cuenca del Besaya.

Nos centraremos en este apartado en el conjunto de Venta de la Perra, que tiene dataciones (por TL) de costras superpuestas a unos grabados de tipo no figurativo: MAD-984: $25938 \pm 2157$ BP y MAD-985: $25498 \pm 2752$ BP (Arias et al. 1998-1999: 87). Su correlación con los años radiocarbónicos establecería un término ante quem para los grabados de unos $22000 \mathrm{BP}$ (Arias et al. 1998-1999: 88), por lo tanto, antes del final del período Gravetiense.

2. Los conjuntos rupestres del Nalón (Asturias). Aceptamos la homogeneidad entre los conjuntos pertenecientes a este Grupo 1 y otros de la cuenca del Nalón como La Lluera I y II y La Viña. F. J. Fortea $(1989,1992,1994)$ defiende la existencia de dos horizontes gráficos consecutivos en los "santuarios exteriores" de la cuenca del Nalón. El primero comprendería grabados de tipo lineal y el segundo, zoomorfos. En el abrigo de La Viña, algunos grabados del primer horizon- 
te canalizaron una reconstrucción litoquímica sellada por un nivel auriñaciense, mientras que la caída por gelifracción de fragmentos grabados del segundo horizonte en el nivel VIb (Fortea 1992), estableció un término ante quem en el Gravetiense reciente para su datación.

\subsubsection{Grupo 2}

1. Dataciones de la cueva de Pondra (Cantabria). Se dataron por medio de termoluminiscencia (TL) varias costras estalagmíticas superpuestas e infrapuestas a representaciones animales. Incluyen un amplio lapso temporal, pero resultan bastante coherentes entre sí. MAD2057: $22595 \pm 2338$ BP data una costra que recubre parcialmente a un grabado de caballo (figura 9 según González Sainz y San Miguel 2001), apuntando a un momento presolutrense para su realización. MAD-2059: $32946 \pm 3440$ BP fecha una costra infrapuesta a un ciervo en tamponado rojo (figura 16 según Gónzalez Sainz y San Miguel 2001), por lo que la concreción se formó en un momento del Auriñaciense o Gravetiense antiguo, mientras que MAD-2058: $26972 \pm 2747$ $\mathrm{BP}$, correspondiente a la una costra estalagmítica superpuesta a la figura, se formó en un momento del Gravetiense. Por tanto, la figura debió ejecu- tarse en algún momento del Gravetiense, probablemente antiguo, aunque sin poder precisarse con seguridad. Esta datación es coherente con la de la primera figura, y situaría en el Gravetiense, como mínimo, las primeras representaciones del Grupo 2.

2. El panel principal de la zona IV de la cueva de La Garma (Cantabria). En la zona IV de la Galería inferior se encuentra un panel complejo con superposiciones de figuras. En la base se identifican un prótomo de uro y un ciervo y una cierva completos. Por el número de extremidades (dos por par), la perspectiva de los cuernos y orejas (biangular recta) y la técnica empleada (trazo tamponado rojo), parecen paralelizables con las de los conjuntos del Grupo 2. La cierva fue parcialmente cubierta por una costra estalagmítica con tres dataciones por U/Th, que la sitúan en un término ante quem en torno a 26.800 años (unos 24000 BP en años de radiocarbono) (González Sainz, com. pers.).

3. La cierva de Antoliñako Koba (Bizkaia). En la X campaña de excavación (2006), se halló un percutor de arenisca en el contacto entre los niveles Auriñaciense y Gravetiense. Sobre dicho percutor se grabó con trazo simple y único un prótomo de cierva orientado a la izquierda (Aguirre Ruiz de Gopegi 2006: 124) (Fig. 5). Esta pieza tiene gran interés y puede arrojar algo de luz sobre

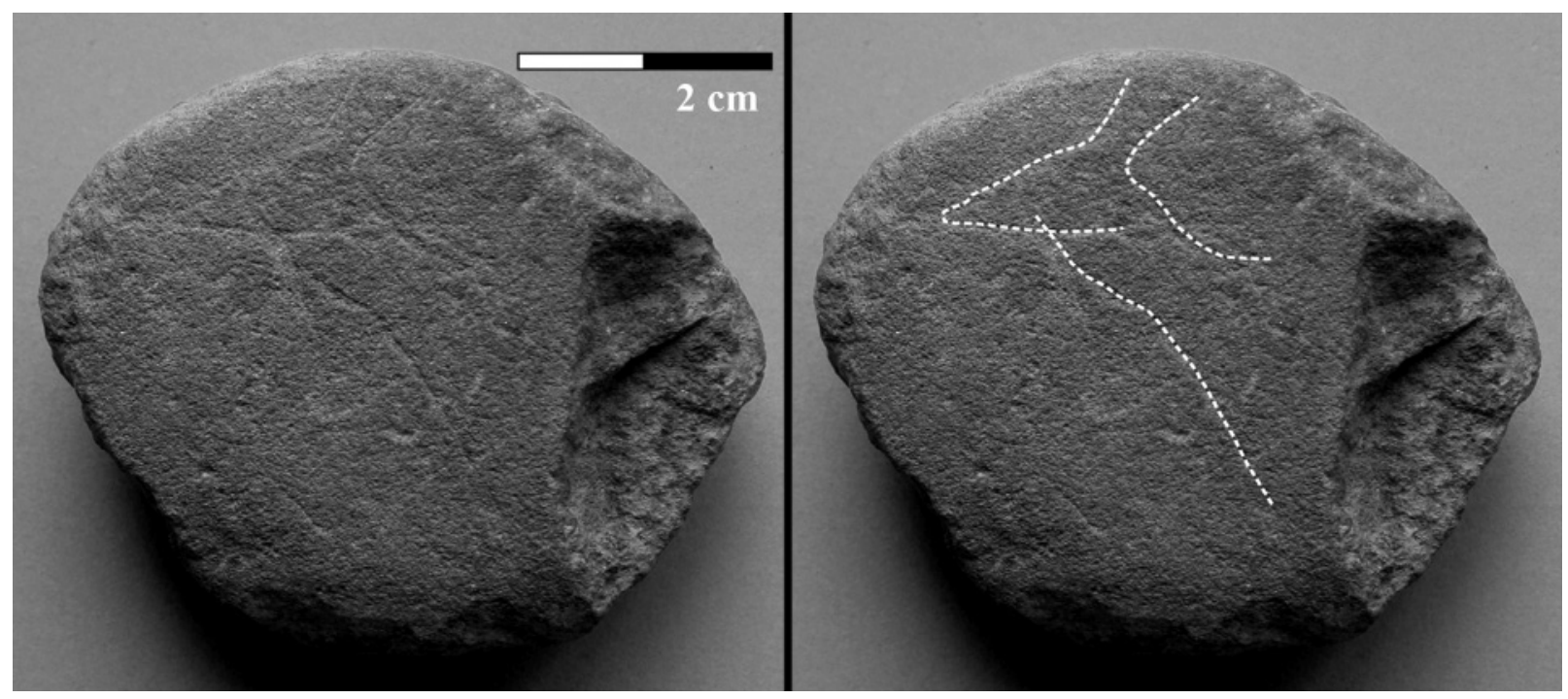

Fig. 5. Fotografía y croquis del percutor de arenisca recuperado durante la excavación de Antoliñako Koba (Bizkaia), con un prótomo de cierva grabado, procedente del contacto entre los niveles Auriñaciense y Gravetiense (fotografía Aguirre Ruiz de Gopegi 2006: 122).

Trab. Prehist., 68, N. ${ }^{\circ}$ 2, julio-diciembre 2011, pp. 259-274, ISSN: 0082-5638 doi: $10.3989 /$ tp.2011.11069 
la datación del arte paleolítico cantábrico, ya que se localizó en un nivel con siete fechas radiocarbónicas coherentes entre sí, en torno al 27000 BP (Aguirre Ruiz de Gopegi, com. pers.).

La figura consta de cuello, cara, dos orejas y el arranque de la línea cervico-dorsal. La forma de representación de la cara (triangular) y de las orejas, una como prolongación de la línea frontonasal y la otra de la línea cervico-dorsal y con un vacío entre ambas, es convencional entre las ciervas en tamponado rojo de varios conjuntos del Grupo 2 (La Pasiega A, Arenaza, Covalanas...). Con esta evidencia, sumada a las anteriores, se podría proponer un origen ya a inicios del Gravetiense para los conjuntos con figuras en tamponado rojo, lo que difiere mucho de la tradicional datación de Leroi-Gourhan (1965) en el Magdaleniense inicial.

\subsubsection{Grupo 3}

Este grupo es excepcional ya que disponemos de un buen número de dataciones directas por C14-AMS de algunas representaciones ejecutadas con carbón vegetal. Así pues, contamos con bases fiables para apoyar una cronología absoluta. Entre los conjuntos seleccionados para nuestro estudio, algunas figuras rupestres de Covaciella se han datado por este método en el Magdaleniense reciente (Fortea et al. 1995). Como cabía esperar, el análisis de correspondencias ha revelado una clara afinidad entre Covaciella y los conjuntos de Santimamiñe y Urdiales, lo que podría avalar una asignación cronológica similar. La tabla 2 presenta dataciones directas (por el método del C14AMS) de figuras parietales zoomorfas de estilo magdaleniense de conjuntos cantábricos.

\subsection{La cronología de los grupos: evaluación}

Uno de los resultados del presente trabajo ha sido refrendar la pertinencia de las tres agrupaciones de centros rupestres cantábricos, definidas usualmente por aspectos técnicos, formales y estilísticos, incorporando la perspectiva de las figuras, su grado de acabado y la temática animal. Estos grupos se diferencian netamente entre sí y tienen un alto grado de homogeneidad y coherencia interna, más allá de la técnica con la que se representan los animales, y de su ubicación al interior o exterior de las cuevas.

Parece comprobado que los conjuntos del Grupo 3 se restringen al período entre el Magdaleniense medio ( $c a .14500 \mathrm{BP}$ ) y el final del Magdaleniense ( $c a .11700 \mathrm{BP}$ ). También resulta poco probable que algunos de los conjuntos de los Grupos 1 y 2 fueran realizados durante el Magdaleniense. De hecho, con los datos de que disponemos tampoco hay pruebas evidentes de que alguno pudiera ser decorado incluso durante el Solutrense, si bien carecemos de argumentos definitivos que nos permitan rechazar esta posibilidad.

La mayor dificultad se encuentra en la valoración cronológica de los Grupos 1 y 2. Los análisis realizados hasta el momento son tan útiles como inexactos. La imprecisión en la mayoría de los casos de las fechas obtenidas por TL y U/Th es de miles de años. Por otro lado, no se fechan directamente los propios motivos, sino los recrecimientos calcíticos que los recubren, que establecen un término ante quem (y, en algunos casos como Pondra, también uno post quem), pero no una cronología directa de las representaciones. Lo mismo ocurre con los fragmentos parietales decorados caídos en niveles estratigráficos bien datados, fechan el desprendimiento, pero no cuánto tiempo antes fueron realizados los motivos.

Por todo ello, la cierva de Antoliñako Koba cobra una cierta relevancia, al ofrecer un paralelismo entre una pieza de arte mobiliar y unas representaciones convencionales en arte parietal (Fig. 5). Como el percutor fue grabado a comienzos del Gravetiense (en torno al 27000 BP), puede servir para afinar un poco más los datos aportados por las dataciones de costras, con términos ante quem en torno al Gravetiense final. Estos paralelismos entre el arte mobiliar y el parietal ya han servido para establecer la cronología de motivos como las "ciervas estriadas" del Magdaleniense inferior cantábrico (Utrilla 1979) o las "cabras en visión frontal" del Magdaleniense reciente (González Sainz et al. 1985).

Sin embargo, la referida imprecisión en las dataciones de estos dos grupos provoca que los datos cronológicos se 'solapen'. Ambos tipos de conjuntos pudieron decorarse en un amplio período del Paleolítico superior antiguo (entre el 36500 y el 21000 BP), en cualquier momento del Auriñaciense o el Gravetiense. ¿Pero este 'solapamiento' es real?, es decir, ¿ambos son sincrónicos en el ám- 


\begin{tabular}{|c|c|c|c|c|}
\hline YACIMIENTO & REFERENCIA & EDAD (BP) & ERROR & FIGURA MUESTREADA/BIBLIOGRAFÍA \\
\hline $\begin{array}{l}\text { Altamira } \\
\quad(\mathrm{C})\end{array}$ & $\begin{array}{l}\text { GifA-98155 } \\
\text { GifA-98156 } \\
\text { GifA-91181 } \\
\text { GifA-96071 } \\
\text { GifA-91330 } \\
\text { GifA-91179 } \\
\text { GifA-96060 } \\
\text { GifA-91254 } \\
\text { GifA-91178 } \\
\text { GifA-96067 } \\
\text { GifA-91249 }\end{array}$ & $\begin{array}{l}13900 \\
14750 \\
14330 \\
14820 \\
\mathbf{1 4 2 5 0} \\
13940 \\
14800 \\
14710 \\
13570 \\
13130 \\
\mathbf{1 4 4 1 0}\end{array}$ & $\begin{array}{l}130 \\
140 \\
190 \\
130 \\
\mathbf{1 8 0} \\
170 \\
150 \\
200 \\
190 \\
120 \\
\mathbf{2 0 0}\end{array}$ & $\begin{array}{c}\text { Cabra XXXVI } \\
\text { Moure y González Sainz } 2000 \\
\text { Bisonte XXXIII } \\
\text { Valladas } \text { et al. } 1992 \\
\text { Moure } \text { et al. } 1996 \\
\text { Bisonte XXXVI } \\
\text { Valladas } \text { et al. } 1992 \\
\text { Moure } \text { et al. } 1996 \\
\text { Bisonte XLIV } \\
\text { Valladas } \text { et al. } 1992 \\
\text { Moure } \text { et al. } 1996\end{array}$ \\
\hline $\begin{array}{l}\text { Covaciella } \\
\quad \text { (A) }\end{array}$ & $\begin{array}{l}\text { GifA-95281 } \\
\text { GifA-95370 } \\
\text { GifA-95364 } \\
\text { GifA-95362 }\end{array}$ & $\begin{array}{l}14060 \\
\mathbf{1 3 7 0 0} \\
14260 \\
\mathbf{1 4 2 6 0}\end{array}$ & $\begin{array}{l}140 \\
\mathbf{1 4 0} \\
130 \\
\mathbf{1 8 0}\end{array}$ & $\begin{array}{c}\text { Bisonte } 25 \\
\text { Fortea et al. } 1995 \\
\text { Bisonte } 26 \\
\text { Fortea et al. } 1995\end{array}$ \\
\hline $\begin{array}{l}\text { El Castillo } \\
\text { (C) }\end{array}$ & $\begin{array}{l}\text { GifA-96079 } \\
\text { GifA-91004 } \\
\text { GifA-96068 } \\
\text { GifA-91172 } \\
\text { GifA-95136 } \\
\text { GifA-95146 } \\
\text { GifA-96077 } \\
\text { GifA-96078 } \\
\text { GifA-95375 } \\
\text { GifA-95227 } \\
\text { GifA-95226 } \\
\text { GifA-98152 } \\
\text { GifA-98151 } \\
\text { GifA-98159 }\end{array}$ & $\begin{array}{l}12620 \\
13060 \\
13520 \\
12910 \\
10510 \\
11270 \\
10720 \\
10740 \\
\mathbf{1 2 3 9 0} \\
13520 \\
13570 \\
13710 \\
14090 \\
\mathbf{1 3 5 1 0}\end{array}$ & $\begin{array}{r}110 \\
200 \\
130 \\
180 \\
\\
100 \\
80 \\
100 \\
100 \\
190 \\
120 \\
130 \\
140 \\
150 \\
190\end{array}$ & $\begin{array}{c}\text { Bisonte } 18 \mathrm{a} \\
\text { Valladas et al. } 1992 \\
\text { Moure y González Sainz } 2000 \\
\text { Bisonte } 18 \mathrm{~b} \\
\text { Valladas et al. } 1992 \\
\text { Bisonte 18c } \\
\text { Moure y González Sainz } 2000\end{array}$ \\
\hline $\begin{array}{l}\text { La Garma } \\
\text { (C) }\end{array}$ & GifA-102581 & 13780 & 150 & Bisonte vertical. Zona XI (inédito) \\
\hline $\begin{array}{l}\text { La Pasiega } \mathrm{C} \\
\text { (C) }\end{array}$ & $\begin{array}{l}\text { GifA-98164 } \\
\text { GifA-98165 }\end{array}$ & $\begin{array}{l}11990 \\
12460\end{array}$ & $\begin{array}{l}170 \\
160\end{array}$ & $\begin{array}{l}\text { Bisonte } 88 \\
\text { Moure y González Sainz } 2000\end{array}$ \\
\hline \multirow{2}{*}{$\begin{array}{l}\text { Las Monedas } \\
\text { (C) }\end{array}$} & $\begin{array}{l}\text { GifA-95203 } \\
\text { GifA-95284 }\end{array}$ & $\begin{array}{l}12170 \\
11630\end{array}$ & $\begin{array}{l}110 \\
120\end{array}$ & $\begin{array}{c}\text { Cabra } 16 \\
\text { Moure et al. } 1996\end{array}$ \\
\hline & GifA-95360 & 11950 & 120 & $\begin{array}{c}\text { Caballo } 20 \\
\text { Moure et al. } 1996 \\
\end{array}$ \\
\hline $\begin{array}{l}\text { Llonin } \\
\text { (A) }\end{array}$ & $\begin{array}{l}\text { GifA-98205 } \\
\text { GifA-98206 }\end{array}$ & $\begin{array}{l}13540 \\
\mathbf{1 3 2 6 0}\end{array}$ & $\begin{array}{l}170 \\
220\end{array}$ & $\begin{array}{c}\text { Bisonte } 4 \\
\text { Fortea } 2002\end{array}$ \\
\hline $\begin{array}{l}\text { Peña Candamo } \\
\text { (A) }\end{array}$ & GifA-98172 & 13870 & 120 & $\begin{array}{c}\text { Ciervo herido del Muro de los Grabados } \\
\text { Fortea } 2002\end{array}$ \\
\hline
\end{tabular}

Tab. 2. Dataciones directas (C14-AMS) de algunas figuras zoomorfas de estilo magdaleniense de conjuntos cantábricos (A: Asturias; C: Cantabria). En negrita, los datos de la fracción ácido-húmica, y en cursiva, los resultados poco coherentes con ésta. 
bito cantábrico? ¿O por el contrario, se debe exclusivamente a la escasa precisión resultante hasta ahora de nuestros métodos de análisis?

Creemos que existen dos hipótesis principales para interpretar las diferencias que muestran las representaciones de ambos grupos:

1. Hipótesis cronológica. Fueron realizados por unos grupos humanos distanciados cronológicamente y con diferentes comportamientos simbólicos que se plasman en sus modos de expresión artística.

2. Hipótesis técnico-funcional. Los mismos grupos humanos decoraron sincrónicamente ambos tipos de conjuntos. Las diferencias en la expresión gráfica se deben a una cuestión técnica (grabado frente a pintura) y/o funcional (santuarios exteriores frente a santuarios interiores). Por lo tanto, las particularidades de los conjuntos con grafías zoomorfas punteadas mostrarían la adaptación de los "santuarios exteriores cantábricos" al cambio de técnica y ubicación.

Para intentar iluminar esta cuestión recurriremos de nuevo al análisis multivariante de correspondencias. En esta ocasión incluiremos los datos de conjuntos o subconjuntos asimilados a cronologías antiguas con representaciones descritas como "arcaicas". Se trata de la cueva de Micolón (Cantabria) y de las figuras animales pintadas del Panel de las Manos de la cueva de El Castillo (Cantabria).

Para analizar los zoomorfos de Micolón nos remitimos a Gárate y González Sainz (2010), ya que incluyen algunas figuras nuevas. Para el Panel de las Manos hemos combinado los calcos presentes en Alcalde del Río et al. 1911: 118Fig.106, y pl. LXV, con las últimas correcciones (Gárate 2006; Ruiz Redondo 2010). El resultado del análisis individual de las representaciones se muestra en la tabla 3.

Lo interesante de ambos conjuntos es que se pintaron en zonas interiores de las cavidades. Nuestra hipótesis es que, si a pesar de sus diferencias técnicas y de ubicación con respecto a los conjuntos del Grupo 1, se aproximan más a ellos por criterios estilísticos (temática animal, grado de integridad, tipo de perspectiva...), nos decantaríamos por la hipótesis cronológica.

El análisis multivariante de correspondencias (Fig. 6) ha revelado una gran afinidad entre Micolón, el Panel de las Manos de El Castillo y los conjuntos del Grupo 1. El Panel de las Manos se encuentra más distanciado en la gráfica del resto

\begin{tabular}{|c|c|c|c|}
\hline & & Micolón & El Castillo \\
\hline \multirow{4}{*}{ A } & Caballo & 22,22 & 8,33 \\
& Ciervo & 22,22 & 0 \\
& Cierva & 11,11 & 0 \\
& Uro & 0 & 0 \\
& Bisonte & 0 & 83,33 \\
& Bóvido indet. & 0 & 0 \\
& Cabra & 22,22 & 0 \\
& Reno & 0 & 0 \\
& Oso & 5,56 & 0 \\
& Cuadrúpedo indet. & 16,67 & 8,33 \\
\hline \multirow{4}{*}{ B } & A + Aa + B & 33,33 & 50 \\
& C + D & 61,11 & 50 \\
& E + F & 5,56 & 0 \\
\hline \multirow{4}{*}{ C } & PA & 66,67 & 91,67 \\
& BR & 27,78 & 8,33 \\
& BO & 5,56 & 0 \\
\hline \multirow{4}{*}{} & UN & 0 & 0 \\
\hline
\end{tabular}

Tab. 3. Arte paleolítico cantábrico. Resultados del análisis cuantitativo considerando la especie animal (A) (indet. Indeterminado), el grado de integridad de la figura (B) (véase Fig. 2) y la perspectiva general de las representaciones (C) (véase Tab. 1) de Micolón (Rionansa, Cantabria) y el Panel de las Manos de la cueva de El Castillo (Puente Viesgo, Cantabria), expresados como el porcentaje que representan sobre el total de figuras animales de cada conjunto cántabro.

de conjuntos de este grupo. Este hecho se puede explicar por el alto porcentaje de bisontes representados (más del 80\%). Ya apuntamos que en los conjuntos del Grupo 1, la distribución temática parece seguir unas pautas geográficas. Como el resto de conjuntos del grupo que hemos analizado están en la zona occidental, la componente "bisonte" provoca una ligera separación de este subconjunto. Si hubiéramos incluido en nuestro análisis otros "santuarios exteriores cantábricos" de la cuenca del Asón (Venta de la Perra, La Luz...) probablemente se situarían muy próximos al $\mathrm{Pa}$ nel de las Manos, por el alto porcentaje de bisontes que contienen.

Estos resultados en cierto modo nos enfrentan con la hipótesis técnico-funcional que planteábamos con anterioridad. Demuestran que la técnica y la ubicación de las representaciones no condicionan las diferencias observadas entre los Grupos 1 y 2 en materia de perspectiva y esquema 


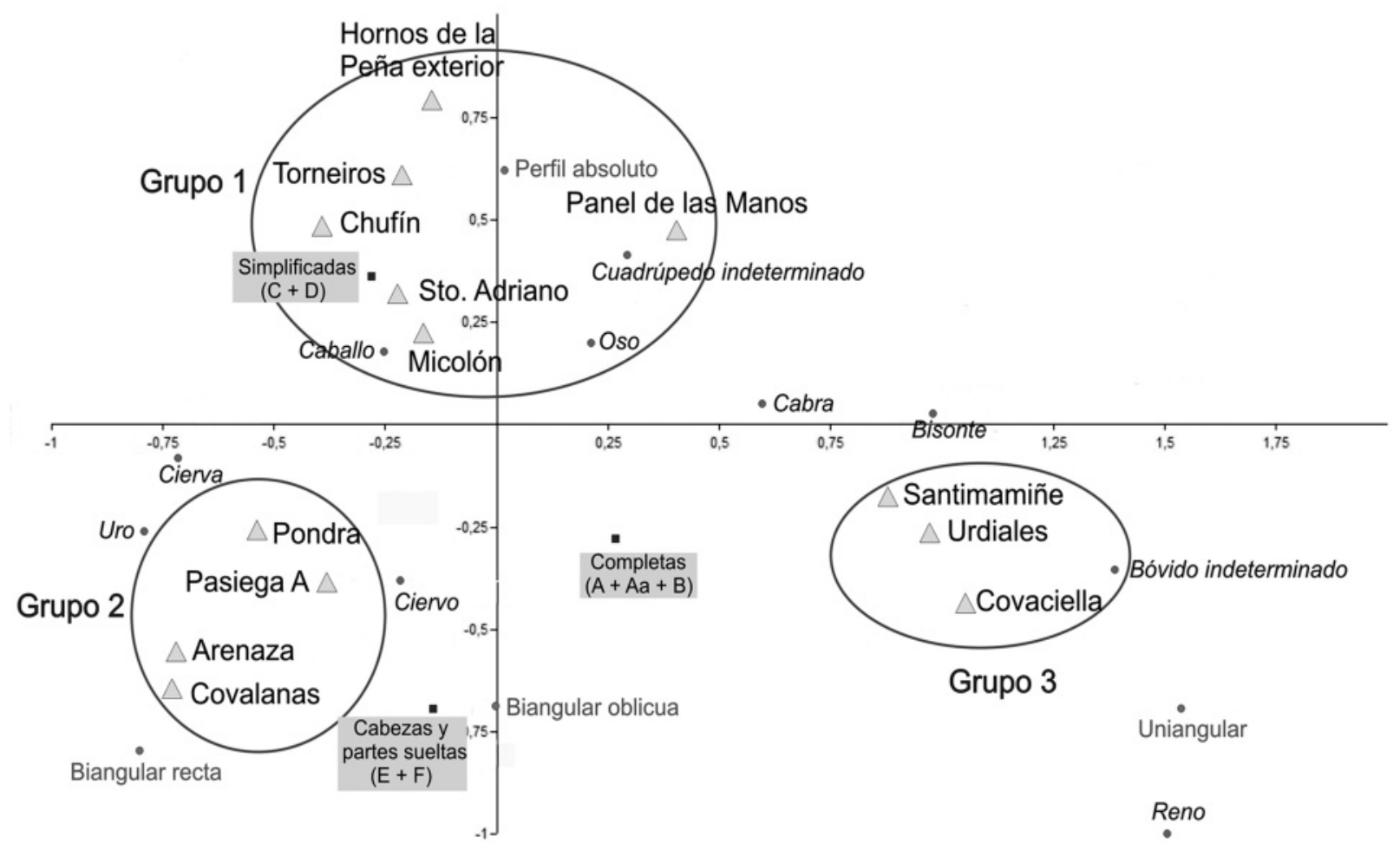

Fig. 6. Arte paleolítico cantábrico. Análisis multivariante de correspondencias que incluye a los conjuntos cántabros de Micolón (Rionansa) y el Panel de las Manos de la cueva de El Castillo (Puente Viesgo). Los conjuntos estudiados se simbolizan mediante un triángulo y las agrupaciones de conjuntos observables se destacan con unas elipses.

compositivo. Es decir, posiblemente ciertos conjuntos y subconjuntos interiores -como los analizados- pertenecen a un mismo horizonte gráfico que los "santuarios exteriores cantábricos". Tienen mayor afinidad de estilo con éstos que con los conjuntos del Grupo 2. Por lo tanto, nos decantamos por la hipótesis cronológica para explicar las diferencias entre los Grupos 1 y 2.

\subsection{Otras propuestas cronológicas}

Hemos comparado nuestra propuesta cronológica con otras relativas al arte paleolítico cantábrico (Fig. 7). La primera se asemeja a la cronología propuesta por A. Leroi-Gourhan (1965) para los conjuntos cantábricos. La defienden F. J. Fortea (1994, 2001) o J. L. Sanchidrián (2001) que proponen un horizonte pre-figurativo bastante amplio: desde el comienzo del Paleolítico superior hasta las fases centrales del Gravetiense. Durante este período, estos autores no admiten representaciones figurativas en el Cantábrico. Sitúan las de nuestro Grupo 1 (horizonte II del Nalón) entre el Gravetiense avanzado y el Solutrense superior y las del Grupo 2 entre el Solutrense y el Magdaleniense inferior. En la cronología del Grupo 3, que estos autores denominan "Arte del Magdaleniense medio y superior", coinciden las tres propuestas.

C. González Sainz defiende en la última década la segunda ordenación. Nuestra propuesta y la suya son similares, con algunas salvedades. En primer lugar, sugiere una cronología más dilatada para los Grupos 1 y 2, que implica un mayor tiempo de coexistencia de ambos tipos de conjuntos. Además, su máximo desarrollo se situaría en un momento más reciente -el Grupo 1 en el Gravetiense y el Grupo 2 en el Solutrense- que en nuestra propuesta. Una última diferencia que, en realidad, es más bien de procedimiento, estriba en que este autor entiende todos los conjuntos interiores antiguos (fechados, como los de manos en negativo, o por ecos estilísticos con los conjuntos de grabados exteriores) en el vector que más ade- 


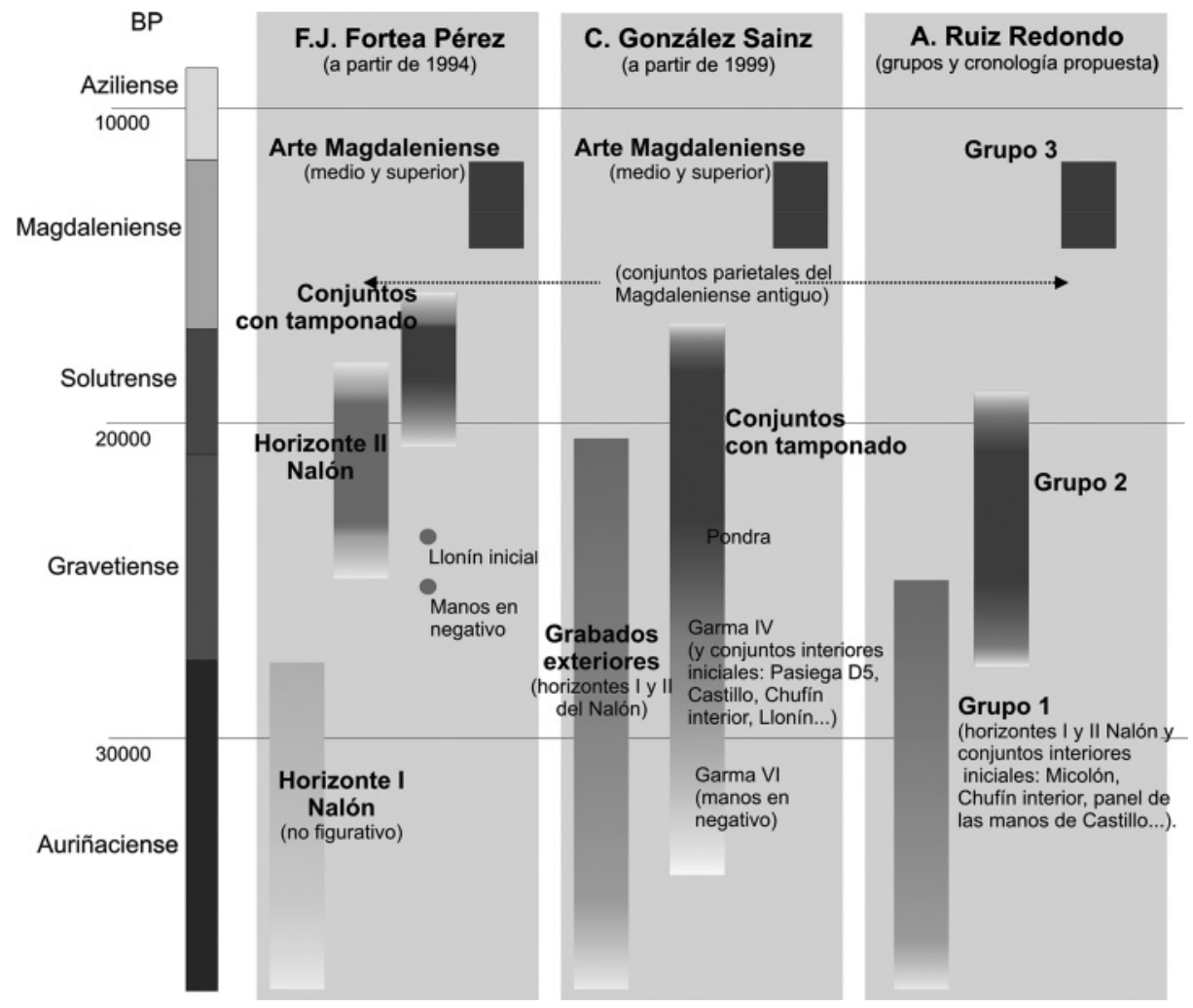

Fig. 7. Comparación de las tres propuestas cronológicas descritas para el arte paleolítico cantábrico (de izquierda a derecha): Fortea (desde 1994), González Sainz (desde 1999) y la defendida en este trabajo.

lante concluirá en los de abundante tamponado (nuestro Grupo 2). En cambio, nosotros (valorando la asociación observada en el análisis multivariante) preferimos integrar algunos, como Chufín interior, el horizonte de los bisontes del Panel de las Manos de El Castillo, Micolón..., en nuestro Grupo 1, basándonos en datos cronológicos y en las características de sus figuras zoomorfas.

\section{CONCLUSIONES}

A la luz de los datos anteriores, proponemos una sucesión temporal entre los grupos. El Grupo 1 podría desarrollarse durante el período $\mathrm{Au}$ riñaciense. Ello encajaría bien con los datos aportados por González Sainz (2000: 266) y con las evidencias estratigráficas de La Viña. Los conjuntos del Grupo 2 se iniciarían en el Gravetiense antiguo. No nos atrevemos a precisar su amplitud, que, en todo caso, no creemos llegara hasta los inicios del Magdaleniense como propuso Leroi-Gourhan para Covalanas. En resumen:
1. Los conjuntos más antiguos del Grupo 1 se comenzaron a inicios del Paleolítico superior, en un momento inconcreto del Auriñaciense ( $c a$. $35000 \mathrm{BP}$ ), y los más recientes en las fases centrales del período Gravetiense (ca. $25000 \mathrm{BP}$ ).

2. Los primeros conjuntos del Grupo 2 -con un grado aceptable de certeza- se iniciaron con el Gravetiense ( $c a .27000 \mathrm{BP}$ ) y creemos que los más recientes no fueron posteriores al Solutrense inferior (ca. $19000 \mathrm{BP}$ ). La posibilidad de que su desarrollo incluyera gran parte o la totalidad del tecno-complejo Solutrense no es desechable, pero faltan dataciones, directas e indirectas, para avalarla.

3. Los conjuntos del Grupo 3 tienen un marco cronológico mejor definido y más restringido, que abarca desde el Magdaleniense medio ( $c a$. 14500 BP) al final del Magdaleniense (ca. 11700 BP).

En este esquema destaca claramente un vacío artístico entre las fases centrales del Solutrense ( $c a .19000$ BP) y el Magdaleniense medio ( $c a$. 14500 BP). No contemplamos la posibilidad de que sea un vacío real, sino que es consecuencia 
de la selección de conjuntos para este estudio. Existen uno o varios grupos de figuras fechadas entre los Grupos 2 y 3 . Por ejemplo, los grabados de "ciervas estriadas" de Altamira o El Castillo. Sus evidentes paralelos con otras de arte mobiliar bien contextualizadas permiten datarlas en el Magdaleniense inferior (Utrilla 1979). También hay otras representaciones de difícil inclusión en nuestros Grupos y que tradicionalmente se han considerado solutrenses: por ejemplo, las del Panel 14 de Chufín (que pueden ser producto de la ocupación solutrense detectada en la excavación del vestíbulo), algunas de los conjuntos de Tito Bustillo, de las Galerías B y C de La Pasiega, de Las Chimeneas, de Altamira...

En ningún caso abogamos por la existencia de un lapso del Paleolítico superior en que se abandone la creación artística en el Cantábrico, es más, creemos que esta posibilidad sólo es asumible desde un punto de vista histórico-cultural que no compartimos.

\section{AGRADECIMIENTOS}

El presente trabajo forma parte de una investigación dirigida por el Dr. César González Sainz y financiada por una beca predoctoral de la Universidad de Cantabria. Sus correcciones, las de David Cuenca Solana y Eduardo Palacio Pérez han contribuido a la mejora de este texto.

\section{BIBLIOGRAFÍA}

Aguirre Ruiz de Gopegi, M. 2006: "Antoliñako koba (Gautegiz-Arteaga). X Campaña". Arkeoikuska 06: 121-124.

Alcalde del Río, H.; Breuil, H. y Sierra, L. 1911: Les cavernes de la région cantabrique. Imprimerie Veuve A. Chéne. Mónaco.

Almagro Basch, M. 1973: "Las pinturas y grabados rupestres de la cueva de Chufín. Riclones (Santander)". Trabajos de Prehistoria 30: 9-67.

Almagro, M.; Cabrera, V. y Bernaldo de Quirós, F. 1977: "Nuevos hallazgos de arte rupestre en Cueva Chufín. Riclones (Santander)". Trabajos de Prehistoria 34: 9-29.

Apellániz, J. M. 1982: El Arte Prehistórico del País Vasco y sus vecinos. Ed. Desclée de Brouwer. Bilbao.

Aranzadi, T.; Barandiaran, J. M. y Eguren, E. 1976: "Exploraciones de la caverna de Santimamiñe (Basondo-Cortézubi). I. Figuras rupestres". En J. M. de Barandiaran: Obras completas $I X$. Ed. La Gran Enciclopedia Vasca. Bilbao: 13-89.

Arias, P.; Calderón, T.; González Sainz, C.; Millán, A.; Moure, A.; Ontañón, R. y Ruiz Idarraga, R. 199899: "Dataciones absolutas para el arte rupestre paleolítico de Venta de la Perra (Carranza, Bizkaia)". Kobie XXV: 85-92.

Aujoulat, N. 1993: "La perspective". En N. Aujoulat, C. Barrière, R. Bégouën, J. M. Bouvier, J. Clottes, M. Crémadès, M. Dauvois, V. Féruglio, J. Gaussen, M. Lorblanchet, Y. Martin, F. Rouzaud, D. Sacchi y G. Sauvet: L'art pariétal paléolithique: techniques et méthodes d'étude. Comité des Travaux Historiques et Scientifiques. París: 281-288.

Barceló, J. A. 2007: Arqueología y estadística (1): Introducción al estudio de la variabilidad de las evidencias arqueológicas. Universitat Autònoma de Barcelona, Bellaterra. Barcelona.

Breuil, H. 1952: Quatre cents siècles d'art parietal. Editions Max Fourny. París.

Breuil, H.; Obermaier, H. y Alcalde del Río, H. 1913: La Pasiega à Puente-Viesgo (Santander). Institut de Paléontologie Humaine. Mónaco.

Conkey, M. 1985: "Ritual communication, social elaboration, and the variable trajectories of Paleolithic Material Culture". En T. D. Price y J. A. Brown (eds.): Prehistoric Hunter-Gatherers: the emergence of cultural complexity. Academic Press. San Diego (California): 299-323.

Fortea Pérez, F. J. 1989: "Cuevas de La Lluera. Avance al estudio de sus artes parietales". En M. R. González Morales (ed.): Cien años después de Sautuola. Estudios en homenaje a Marcelino Sanz de Sautuola en el Centenario de su muerte. Diputación Regional de Cantabria. Santander: 187-202.

Fortea Pérez, F. J. 1992: "Abrigo de La Viña. Informe de las campañas 1987 a 1990”. Excavaciones Arqueológicas en Asturias 1987-1990: 19-28.

Fortea Pérez, F. J. 1994: "Los santuarios 'exteriores' en el Paleolítico cantábrico". Complutum 5: 203220.

Fortea Pérez, F. J. 2001: "Los comienzos del Arte Paleolítico en Asturias: aportaciones desde una arqueología contextual no-postestilística". Zephyrus LIII-LIV: 177-216.

Fortea Pérez, F. J. 2002: “Trente-neuf dates C14-SMA pour l'art parétal paléolithique des Asturies". Bulletin de la Societé Préhistorique Ariège-Pyrénées LVII: 7-28.

Fortea Pérez, F. J. 2005: "Los grabados exteriores de Santo Adriano (Tuñón. Sto. Adriano. Asturias)”. Munibe 57: 23-52.

Fortea Pérez, F. J. 2008: “Covaciella”. En J. Rodríguez Muñoz (ed.): La Prehistoria en Asturias. Cuevas con arte. La Nueva España. Oviedo: 142-156. 
Fortea Pérez, F. J. y Quintanal, J. M. 1995: "Santo Adriano". Excavaciones Arqueológicas en Asturias 1991-1994: 275-276.

Fortea Pérez, F. J.; Rodríguez Asensio, J. A. y Ríos González, S. 1999: "La grotte de Los Torneiros (Castañedo del Monte, Tuñon, Asturies, Espagne)". International Newsletter On Rock Art 24: 8-11.

Fortea Pérez, F. J.; Rodríguez Otero, V.; Hoyos Gómez, M.; Federación Asturiana de Espeleología; Valladas, H. y Torres, T. 1995: “Covaciella”. Excavaciones Arqueológicas en Asturias 1991-1994: 258-270.

Gálvez, N. y Cacho, R. 2010: “Hornos de la Peña”. En B. Malpelo e I. Castanedo (eds.): Las cuevas con arte paleolítico en Cantabria. Monografías arqueológicas de la Asociación Cántabra para la Defensa del Patrimonio Subterráneo 2. Santander: 145-150.

Gárate Maidagan, D. 2004: "Nuevas investigaciones sobre el arte paleolítico de la cueva de Arenaza (Galdames, Bizkaia)". Munibe 56: 3-17.

Gárate Maidagan, D. 2006: "Nuevos datos en torno al inicio del Arte Parietal Cantábrico: la aportación de un caballo inédito en el Panel de las Manos de la Cueva del Castillo (Puente Viesgo, Cantabria)". Sautuola XII: 112-119.

Gárate Maidagan, D. 2010: Las ciervas punteadas en las cuevas del Paleolítico. Una expresión pictórica propia de la cornisa cantábrica. Munibe, suplemento 33. Sociedad de Ciencias Aranzadi. San Sebastián.

Gárate Maidagan, D. y González Sainz, C. 2010: “Micolón". En B. Malpelo e I. Castanedo (eds.): Las cuevas con arte paleolitico en Cantabria. Monografías arqueológicas de la Asociación Cántabra para la Defensa del Patrimonio Subterráneo 2. Santander: 77-83.

Gárate Maidagan, D.; Jiménez, J. M. y Ortiz, J. 2002: "El Arte rupestre paleolítico de la cueva de Arenaza (Galdames, Bizkaia)". Kobie XXVI: 5-64.

García Díez, M. y Eguizabal Torre, J. 2003: La cueva de Covalanas. El grafismo rupestre y la definición de territorios gráficos en el paleolítico cantábrico. Ayuntamiento de Ramales de la Victoria y Gobierno de Cantabria. Santander.

González Sainz, C. 2000: "Representaciones arcaicas de bisonte en la región Cantábrica”. Homenaje al Profesor Vallespí, SPAL. Revista de Prehistoria y Arqueología 9: 257-277.

González Sainz, C. 2007: “Quelques particularités des centres pariétaux paléolithiques dans la région cantabrique". Bulletin de la Société Prehistorique de l'Ariège 62: 19-36.

González Sainz, C. 2010: “Chufín”. En B. Malpelo e I. Castanedo (eds.): Las cuevas con arte paleolitico en Cantabria. Monografías arqueológicas de la Asociación Cántabra para la Defensa del Patrimonio Subterráneo 2. Santander: 71-76.
González Sainz, C. y Balbín Behrmann, R. 2010: “La Pasiega". En B. Malpelo e I. Castanedo (eds.): Las cuevas con arte paleolitico en Cantabria. Monografías arqueológicas de la Asociación Cántabra para la Defensa del Patrimonio Subterráneo 2. Santander: 191-204.

González Sainz, C. y Gárate Maidagan, D. 2006: “Los grabados y pinturas rupestres de la cueva de El Rincón, en el contexto artístico del desfiladero del río Carranza (Bizkaia-Cantabria)". Homenaje a Francisco Jordá Cerdá, Zephyrus LIX: 135-154.

González Sainz, C.; Muñoz, E. y San Miguel, C. 1985: "Los grabados rupestres paleolíticos de la cueva del Otero (Secadura, Cantabria)". Sautuola IV: $155-164$.

González Sainz, C. y San Miguel, C. 2001: Las cuevas del desfiladero: Arte rupestre paleolítico en el valle del río Carranza (Cantabria-Vizcaya). Universidad de Cantabria. Santander.

Gorrotxategi, X. 2000: Arte paleolítico parietal de Bizkaia. Anejos de Kobie 2. Diputación Foral de Bizkaia. Bilbao.

Leroi-Gourhan, A. 1965: Préhistoire de l'art occidental. Mazenod. París.

Leroi-Gourhan, A. 1983. Los primeros artistas de Europa. Ed. Encuentro. Madrid.

Montes, R.; Muñoz Fernández, E. y Morlote Expósito, J. M. 2005: Cueva Urdiales (Castro Urdiales, Cantabria): Estudio Geoarqueológico y Arte Rupestre Paleolítico. Ayto. de Castro Urdiales. Santander.

Moure Romanillo, A. y González Sainz, C. 2000. "Cronología del arte paleolítico cantábrico: últimas aportaciones y estado actual de la cuestión". Actas do $3 .^{\circ}$ Congresso de Arqueologia Peninsular (Vila Real 1999) 2: 461-473. Porto.

Moure Romanillo, A.; González Sainz, C.; Bernaldo de Quirós, F. y Cabrera Valdés, V. 1996: "Dataciones absolutas de pigmentos en cuevas cantábricas: Altamira, El Castillo, Chimeneas y Las Monedas". En A. Moure (ed.): "El Hombre Fósil" 80 años después. Universidad de Cantabria. Santander: 295324.

Moure Romanillo, A.; González Sainz, C. y González Morales, M. R. 1991: Las cuevas de Ramales de la Victoria. Arte rupestre paleolítico en las cuevas de Covalanas y La Haza. Universidad de Cantabria. Santander.

Ríos González, S.; García de Castro Valdés, C.; Rasilla Vives, M. de la y Fortea, F. J. 2007: Arte rupestre prehistórico del Oriente de Asturias. Nobel. Oviedo.

Ruiz Redondo, A. 2010: "Una nueva revisión del Panel de las Manos de la cueva de El Castillo (Puente Viesgo, Cantabria)". Munibe 61: 17-27.

Sanchidrián Torti, J. L. 2001: Manual de Arte Prehistórico. Ariel Prehistoria. Barcelona. 
Utrilla, P. 1979: “Acerca de la posición estratigráfica de los cérvidos y otros animales de trazo múltiple en el Paleolítico Superior Español". Caesaraugusta 49-50: 65-72.

Valladas, H.; Cachier, H.; Maurice, P.; Bernaldo de Quirós, F.; Cabrera, V.; Uzquiano, P. y Arnold, M. 1992: "Direct radiocarbon dates for prehistoric paintings at the Altamira, El Castillo and Niaux caves". Nature 357: 68-70.
Valladas, H.; Tisnérat-Laborde, N.; Cachier, H.; Arnold, M.; Bernaldo de Quirós, F.; Cabrera, V.; Clottes, J.; Courtin, J.; Fortea, F. J.; González Sainz, C. y Moure, A. 2001: "Radiocarbon AMS dates for Paleolithic Cave Paintings". Radiocarbon 43: 977-986.

Villaverde, V. 1994: Arte Paleolitico de la Cova del Parpalló: estudio de la colección de plaquetas y cantos grabados y pintados I. Diputació, Servei d'Investigació Prehistòrica. Valencia. 